\title{
The reoxygenation injury: Is it clinically important?
}

\author{
Bradley S. Allen, MD
}

See related article on page 105.
From the Division of Cardiovascular Surgery, The Heart Institute for Children, Hope Children's Hospital, Oak Lawn, Ill.

Received for publication Jan 7, 2002; accepted for publication Feb 8, 2002.

Address for reprints: Bradley S. Allen, MD, The Heart Institute for Children, Hope Children's Hospital, 4440 West 95th St, Oak Lawn, IL 60453 (E-mail: Brad@ THIC. com).

J Thorac Cardiovasc Surg 2002;124:16-9

Copyright ( $\odot 2002$ by The American Association for Thoracic Surgery

0022-5223/2002 \$35.00+0 $\quad \mathbf{1 2 / 1 / 1 2 4 6 7 3}$

doi: $10.1067 / \mathrm{mtc} .2002 .124673$

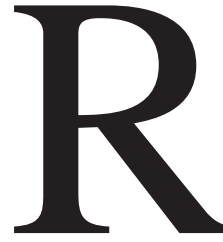

epair of cyanotic congenital heart defects necessitating cardiopulmonary bypass $(\mathrm{CPB})$ is becoming more frequent in infants and neonates. Despite apparently successful surgical correction, postoperative myocardial and pulmonary dysfunction continues to be a major contributor to morbidity and mortality and is more severe than after repair of acquired defects in adults with normoxic conditions. ${ }^{1-3}$ The neonatal heart also has a reduced response to inotropic agents compared with the adult heart. ${ }^{1,2}$ Thus, preservation of myocardial function in neonates during cardiac operations assumes even greater importance, because a perioperative insult is less well tolerated and more difficult to treat.

Congenital malformations of the heart frequently lead to physiologic abnormalities ("stress") that are quite different from those seen in the adult, and so the concerns during $\mathrm{CPB}$ are not necessarily the same. The most common preoperative stress in adults is ischemia, secondary to coronary artery disease, and the major concern is avoidance of a "regional" myocardial reperfusion injury with the reintroduction of blood. ${ }^{4}$ In contrast, the most common preoperative stress in pediatric patients is hypoxia (cyanosis). ${ }^{1,2}$ The major concern, therefore, is whether a reoxygenation injury (similar to a reperfusion injury) occurs with the abrupt reintroduction of oxygen. The occurrence of such an injury could be even more detrimental, as it would result in "global "damage, since hypoxia affects the entire body, not just the heart.

Acute hypoxia and acidosis may occur as a consequence of many congenital heart defects and can result in depletion of glycogen, adenosine triphosphate, and Krebs cycle intermediates, leading to myocardial dysfunction. ${ }^{2,5,6}$ Significant acute hypoxia forces the myocardium to rely on anaerobic metabolism, and when acidosis is present, this further heightens these deleterious effects. Chronic hypoxia leads to cyanosis, a condition frequently encountered in infants and children undergoing cardiac operations. Despite compensatory mechanisms, substrate depletion and metabolic derangements are more common in cyanotic hearts than in normoxic hearts. ${ }^{1-3,5,6}$ Moreover, cyanosis depletes the myocardium of endogenous antioxidants, and a growing body of experimental and clinical evidence indicates that this may make the cyanotic immature heart more susceptible to an oxygen-mediated injury when molecular oxygen is restored.7-10

The reversal of hypoxemia occurs with initiation of extracorporeal circulation and precedes the surgical ischemia used for operative repair in children with cyanotic disease. The conventional method of starting CPB in infants and children with hypoxemia is to abruptly raise oxygen tension $\left(\mathrm{Po}_{2}\right)$ to approximately 400 to $500 \mathrm{~mm} \mathrm{Hg}$. Does this sudden reintroduction of oxygen causes a significant "unintended injury" and, if so, can it be prevented? Such an injury might explain why the cyanotic heart is more vulnerable and less tolerant to subsequent surgical ischemia than the normoxic heart. ${ }^{1-3,5,6}$

Corno and colleagues, ${ }^{11}$ as well as others, have documented experimentally that a reoxygenation injury does occur after an acute hypoxic insult. ${ }^{7-9}$ Our studies support this work. ${ }^{3,10,12}$ We subjected neonatal piglets to 60 minutes of acute ventilator hypoxia (fraction of inspired oxygen $\left[\mathrm{FIO}_{2}\right] 8 \%-10 \%$ ) and then abruptly reoxygenated them by increasing the ventilator $\mathrm{FIO}_{2}$ to $100 \%$, or we placed them on $\mathrm{CPB}$ at an $\mathrm{FIO}_{2}$ of $100 \%$, simulating the usual clinical practice. Abrupt reoxygenation by either method caused an oxygen-derived free radical-mediated injury, resulting in a reduction in cardiac output, depressed myocardial function, elevated 
pulmonary vascular resistance, and a reduction in the arterial/alveolar ratio. This injury was independent of the method of reoxygenation; thus, it is related to the sudden reintroduction of oxygen and not the effects of $\mathrm{CPB}$. Conversely, maintaining normoxemia $\left(\mathrm{Po}_{2} 80-100 \mathrm{~mm} \mathrm{Hg}\right)$ rather than hyperoxemia during the initiation of $\mathrm{CPB}$ and then gradually increasing oxygen levels substantially reduced oxidant damage and decreased the extent of myocardial dysfunction. These benefits coincided with the $\mathrm{Po}_{2}-$ dependent nature of the reoxygenation injury, because free radical production and myocardial injury after reoxygenation of isolated heart preparations are proportionate to $\mathrm{Po}_{2} \cdot{ }^{13,14}$ In clinical practice, hyperoxemic CPB is performed routinely but is likely never needed, because $\mathrm{aPo}_{2}$ of 400 to $500 \mathrm{~mm} \mathrm{Hg}$ confers only a negligible increase in oxygen


instances the oxygen saturation is essentially $100 \%$. Moreover, a CPB $\mathrm{Po}_{2}$ of more than $180 \mathrm{~mm} \mathrm{Hg}$ has been associated with impairment of peripheral perfusion. ${ }^{15}$ The avoidance of hyperoxemia during reoxygenation in cyanotic infants to reduce injury may be comparable, in a sense, with controlling the initial reperfusate after ischemia to avoid a reperfusion injury. ${ }^{4}$

Leukocytes may also be active mediators of the reoxygenation injury. Activated white cells have been shown to play a major role in the generation of oxygen-derived free radicals after ischemia, and it seems logical that they should contribute to the reoxygenation injury, since both ischemia and hypoxia subject tissue to low oxygen levels., ${ }^{3,12,16}$ Leukocyte depletion is a readily available method that allows the surgeon to safely minimize the harmful effects of neutrophils, without risking side effects of pharmacologic interventions aimed at altering leukocyte function or preventing the free radical injury through the use of exogenous oxygen radical scavengers. The effect of leukocyte removal was tested in neonatal piglets after the same acute $(60$ minutes) hypoxic stress. By use of leukocyte-depleting filters, the detrimental effects of sudden reoxygenation were prevented to an even greater extent than with gradual reoxygenation (normoxic strategy), with a marked reduction in oxygen-derived free radical formation, preservation of left ventricular contractility and diastolic compliance, maintenance of pulmonary alveolar capillary gas exchange (arterial/alveolar ratio), and only a slight rise in pulmonary vascular resistance. ${ }^{3,10,12}$ In fact, the change in pulmonary vascular resistance was even less than in nonhypoxic animals subjected to $\mathrm{CPB}$, suggesting that leukocyte filtration should be used in all pediatric operations where postoperative pulmonary hypertension could be problematic. Several experimental and clinical studies support this implication and have documented a reduction in pulmonary injury with leukocyte filtration even in noncyanotic infants. ${ }^{17,18}$

Despite these findings, many surgeons still doubt the existence and the clinical significance of suddenly restoring oxygen to the hypoxic heart. They point out that the majority of studies that have documented this injury have used an acute hypoxic injury, which, in contrast to chronic hypoxia in the infant, may not allow sufficient time for compensatory adaptation to develop. This adaptation, they argue, may allow the chronically hypoxic patient to avoid an injury with the reintroduction of oxygen. As such, they believe that this is an unimportant injury, artificially created in the laboratory, and of little clinical significance. The argument of acute versus chronic is perennial. However, in this case I believe the argument is tenuous at best, because postreoxygenation changes seen after acute experimental hypoxemia parallel those reported in cyanotic patients who undergo reoxygenation during CPB. ${ }^{7,8}$ Moreover, we have now confirmed the findings of our acute experimental studies in cyanotic infants using the same biochemical tests. ${ }^{3,10,12}$

In this issue of the Journal, Corno and his associates ${ }^{11}$ attempt to address the major issue in this continuing debate by comparing the results of reoxygenation after acute and chronic ( 2 weeks) hypoxia. To accomplish this goal, they developed a new chronic hypoxic animal model that closely mimics the clinical setting. The model is quite ingenious, as it avoids the problems of previous chronic models that subjected animals to brief periods of normoxia during feeding and cleaning of their cages. These repeated episodes of reoxygenation do not usually occur in the clinical setting and may significantly alter (ie, condition) the response of the hypoxic heart to reoxygenation; in the same way, repeated episodes of ischemia and reperfusion make the ischemic heart more tolerant to subsequent ischemic insults.

Although their model is quite innovative and allowed the animals to undergo chronic hypoxia, the experiment did not exactly mimic the clinical setting, as rats were 5 weeks old before hypoxia. In contrast, most hypoxic patients are hypoxic either immediately after birth or within the first few days of life. However, as pointed out by Corno's group, this is not always true, because some patients (ie, those with tetralogy of Fallot) may not become hypoxic for weeks to months. It is possible that cellular changes (adaptations) may be different if chronic hypoxia is preceded by a prolonged period of normoxia. Nevertheless, this study still has two important lessons. First, despite any cellular adaptations that may develop with chronic hypoxia, an oxygenmediated injury (reoxygenation injury) still occurs with the abrupt reintroduction of oxygen. Second, the injury after chronic hypoxia is greater than after acute hypoxia. Moreover, despite the 5-week delay in initiating chronic hypoxia, the results are identical to our findings in hypoxic patients, where we demonstrated greater oxygen-derived free radical production in cyanotic (chronic hypoxic) infants compared with acutely hypoxic animals. . $^{3,10,12}$ The most probable explanation for these results is that chronically hypoxic ani- 
mals (or patients) often become ischemic during periods of increased stress (tachycardia) or exercise. ${ }^{19,20}$ This subjects them to both a hypoxic and an ischemic stress. In contrast, acute experimental hypoxia usually results in no ischemia. ${ }^{12}$ It is therefore not surprising that a combination of hypoxia and ischemia results in a more severe injury with reperfusion.

On the basis of this extensive experimental and clinical infrastructure, we now routinely use a normoxic CPB strategy combined with leukocyte depletion in all hypoxic (cyanotic), hypertrophied, or high-risk normoxic patients. The $\mathrm{CPB}$ circuit is primed and initiated at a $\mathrm{Po}_{2}$ of 80 to $100 \mathrm{~mm}$ $\mathrm{Hg}$ (normoxic strategy), and the $\mathrm{FiO}_{2}$ is increased slowly to $30 \%$ to $50 \%$ as needed over the next 10 to 20 minutes to maintain a $\mathrm{Po}_{2}$ of 100 to $150 \mathrm{~mm} \mathrm{Hg}$. We resort to higher oxygen levels $\left(\mathrm{FIO}_{2} 100 \%\right)$ only if we require a period of low flow or deep hypothermic circulatory arrest, as Nollert and associates ${ }^{21}$ have shown that under these conditions an increased oxygen content is important for neurologic protection. A leukocyte-depleting filter is placed in the arterial line for the entire procedure, and if a blood prime is used, it is always washed and leukocyte depleted.

To assess the clinical efficacy of this approach, we retrospectively examined all patients undergoing a Norwood procedure at our institution between July 1, 1996, and March 31, 2000. There were 72 patients, 41 with a diagnosis of hypoplastic left heart syndrome (HLHS) and 31 with a variant (HLHV) of HLHS. The overall survival was $78 \%$ (76\% HLHS, 81\% HLHV). More important, there was complete preservation of myocardial function in the patients with HLHS, both initially, as assessed by echocardiogram (shortening fraction preoperatively $37 \% \pm 10 \%$ vs postoperatively $35 \% \pm 11 \%$ ), and several months later, when evaluated by angiogram (ejection fraction $57 \% \pm 7 \%$ ) before the Glenn procedure. In contrast, the surgical survival in the 38 patients undergoing a Norwood procedure in the 2 years before institution of this strategy was only 53\%, and postoperative low output syndrome was a significant problem. I acknowledge that other changes might have accounted for these findings, but I believe these results, as well as the extensive experimental infrastructure, support the safety and efficacy of this approach.

In summary, although the study by Corno and colleagues ${ }^{11}$ does much to further our knowledge, because of the age of the animals at the time of hypoxia, some may still argue that it does not definitively prove that this injury is clinically important. However, it adds another "piece to the puzzle" and leaves less room for those who still cling to the belief that the reoxygenation injury is simply a mirage, and clinically unimportant. Therefore, perhaps the question should be why risk any damage, no matter what the severity, when it is easy to minimize the reoxygenation injury by using a CPB strategy of normoxia and white blood cell filtration.

\section{References}

1. Castaneda AR, Jonas RA, Mayer JE Jr, Hanley FL. Myocardial preservation in the immature heart. In: Castaneda AR, Jonas RA, Mayer JE Jr, Hanley FL, editors. Cardiac surgery of the neonate and infant. Philadelphia: WB Saunders; 1994. p. 41-54.

2. Hammon JW Jr. Myocardial protection in the immature heart. Ann Thorac Surg. 1995;60:839-42.

3. Allen BS, Barth MJ, Ilbawi M. Pediatric myocardial protection: an overview. Semin Thorac Cardiovasc Surg. 2001;13:56-72.

4. Buckberg GD, Allen BS. Myocardial protection management during adult cardiac operations. In: Baue AE, Geha AS, Hammond GL, Laks H, Naunheim KS, editors. Glenn's thoracic and cardiovascular surgery. 6th ed. Stamford (CT): Appleton \& Lange; 1995. p. 1653-87.

5. Silverman N, Kohler J, Levitsky S, Pavel D, Fang R, Feinberg H. Chronic hypoxemia depresses global ventricular function and predisposes to depletion of high energy phosphates during cardioplegic arrest: implications for surgical repair of cyanotic congenital heart defects. Ann Thorac Surg. 1984;37:304-8.

6. del Nido PJ, Mickle DAG, Wilson GJ, Benson LN, Weisel RD, Coles $\mathrm{JG}$, et al. Inadequate myocardial protection with cold cardioplegic arrest during repair of tetralogy of Fallot. J Thorac Cardiovasc Surg. 1988;95:223-9.

7. Teoh KH, Mickle DAG, Weisel RD, Li R, Tumiati L, Coles JG. Effect of oxygen tension and cardiovascular operations on the myocardial antioxidant enzyme activities in patients with tetralogy of Fallot and aorta-coronary bypass. J Thorac Cardiovasc Surg. 1992; 104:159-64.

8. del Nido PJ, Mickle DAG, Wilson G, Benson LN, Coles JG, Trusler GA. Evidence of myocardial free radical injury during elective repair of tetralogy of Fallot. Circulation. 1987;76:174-9.

9. Ihnken K, Morita K, Buckberg GD, Matheis G, Sherman MP, Allen BS, et al. Studies of hypoxemic/reoxygenation injury: without aortic clamping. II. Evidence for reoxygenation damage. J Thorac Cardiovasc Surg. 1995;110:1171-81.

10. Allen BS, Ilbawi MN. Hypoxia, reoxygenation and the role of systemic leukodepletion in pediatric heart surgery. Perfusion. 2001; 16(Suppl):19-29.

11. Corno AF, Milano G, Samaja M, Tozzi P, von Segesser LK. Chronic hypoxia: a model for cyanotic congenital heart defects. J Thorac Cardiovasc Surg. 2002;124:105-12.

12. Allen BS. Hypoxia, reoxygenation and the role of leukodepletion in the intraoperative management of congenital heart disease. In: Matheis G, Moritz A, Scholz M, editors. Leukocyte depletion in cardiac surgeon and cardiology. 1st ed. Basel: Karger AG; 2002. p. 111-34.

13. Gauduel Y, Menasche P, Duvelleroy M. Enzyme release and mitochondrial activity in reoxygenated cardiac muscle: relationship with oxygen-induced lipid perioxidation. Gen Physiol Biophys. 1989;8: 327-40.

14. Hearse D, Humphrey S, Bullock G. The oxygen paradox and the calcium paradox: Two facets of the same problem? J Mol Cell Cardiol. 1978;10:641-68.

15. Joachimsson P, Sjoberg F, Forsman M, Johansson M, Ahn HC, Rutberg H. Adverse effects of hyperoxemia during cardiopulmonary bypass. J Thorac Cardiovasc Surg. 1996;112:812-9.

16. Byrne J, Appleyard R, Lee CC, Couper GS, Scholl FG, Laurence RG, et al. Controlled reperfusion of the regionally ischemic myocardium with leukocyte-depleted blood reduces stunning, the no-reflow phenomenon, and infarct size. J Thorac Cardiovasc Surg. 1992;103:6672.

17. Komai H, Yamamoto F, Tanaka K, Yagihara T, Kawashima Y. Prevention of lung injury during open heart operations for congenital heart defects. Ann Thorac Surg. 1994;57:134-40.

18. Bando K, Pillai R, Cameron DE, Brawn JD, Winkelstein JA, Hutchins GM, et al. Leukocyte depletion ameliorates free radical-mediated lung injury after cardiopulmonary bypass. J Thorac Cardiovasc Surg. 1990;99:873-7. 
19. Boucek RJ Jr, Kasselberg AG, Boerth RC, Parrish MD, Graham TP Jr. Myocardial injury in infants with congenital heart disease: evaluation by creatine kinase MB isoenzyme analysis. Am J Cardiol. 1982;50: 129-35.

20. Graham TP Jr, Erath HG Jr, Buckspan GS, Fisher RD. Myocardial anaerobic metabolism during isoprenaline infusion in a cyanotic ani- mal model: possible cause of myocardial dysfunction in cyanotic congenital heart disease. Cardiovasc Res. 1979;13:401-6.

21. Nollert G, Nagashima M, Bucerius J, Shin'oka T, Lidov HG, du Plessis A, et al. Oxygenation strategy and neurologic damage after deep hypothermic circulatory arrest. II. Hypoxic versus free radical injury. J Thorac Cardiovasc Surg. 1999;117:1172-9.

\section{ON THE MOVE?}

Don't miss a single issue of the journal! To ensure prompt service when you change your address, please photocopy and complete the form below.

Please send your change of address notification at least six weeks before your move to ensure continued service. We regret we cannot guarantee replacement of issues missed due to late notification.

\section{JOURNAL TITLE:}

Fill in the title of the journal here.

\section{OLD ADDRESS:}

Affix the address label from a recent issue of the journal here.

\section{NEW ADDRESS:}

Clearly print your new address here.

Name

Address

City/State/ZIP

\section{COPY AND MAIL THIS FORM TO:}

Mosby

Subscription Customer Service

6277 Sea Harbor Dr

Orlando, FL 32887
OR FAX TO:

407-363-9661

N/ Mosby
OR PHONE:

800-654-2452

Outside the U.S., call

407-345-4000 